\title{
Title
}

\section{Nationwide large-scale data of acute lower gastrointestinal bleeding in Japan uncover detailed etiologies and relevant outcomes: CODE BLUE J-Study}

Naoyoshi Nagata ${ }^{1,2}$; Katsumasa Kobayashi ${ }^{3}$; Atsushi Yamauchi ${ }^{4}$; Atsuo Yamada ${ }^{5}$; Jun Omori $^{6}$; Takashi Ikeya ${ }^{7}$; Taiki Aoyama ${ }^{8}$ Naoyuki Tominaga ${ }^{9}$; Yoshinori Sato ${ }^{10}$; Takaaki Kishino ${ }^{11}$; Naoki Ishii ${ }^{12}$; Tsunaki Sawada ${ }^{13}$; Masaki Murata ${ }^{14}$; Akinari Takao $^{15}$; Kazuhiro Mizukami ${ }^{16}$; Ken Kinjo ${ }^{17}$; Shunji Fujimori ${ }^{18}$; Takahiro Uotani ${ }^{19}$; Minoru Fujita $^{20}$; Hiroki Sato ${ }^{21}$; Sho Suzuki ${ }^{22}$; Toshiaki Narasaka ${ }^{23,24}$; Junnosuke Hayasaka ${ }^{25}$; Tomohiro Funabiki ${ }^{26}$; Yuzuru Kinjo ${ }^{27}$; Akira Mizuki ${ }^{28}$; Shu Kiyotoki ${ }^{29}$; Tatsuya Mikami $^{30}$; Ryosuke Gushima ${ }^{31}$; Hiroyuki Fujii ${ }^{32}$; Yuta Fuyuno ${ }^{33}$; Naohiko Gunji ${ }^{34}$; Yosuke Toya ${ }^{35}$; Kazuyuki Narimatsu ${ }^{36}$; Noriaki Manabe ${ }^{37}$; Koji Nagaike ${ }^{38}$; Tetsu Kinjo $^{39}$; Yorinobu Sumida ${ }^{40}$; Sadahiro Funakoshi ${ }^{41}$; Kana Kawagishi ${ }^{42}$; Tamotsu Matsuhashi $^{43}$; Yuga Komaki ${ }^{44}$; Kuniko Miki ${ }^{1}$; Kazuhiro Watanabe ${ }^{2}$; Masakatsu Fukuzawa $^{45}$; Takao Itoi $^{45}$; Naomi Uemura ${ }^{46,1}$; Takashi Kawai ${ }^{1}$; Mitsuru Kaise ${ }^{6}$

1 Department of Gastroenterological Endoscopy, Tokyo Medical University, Tokyo, Japan

2 Department of Gastroenterology and Hepatology, National Center for Global Health and Medicine, Tokyo, Japan

3 Department of Gastroenterology, Tokyo Metropolitan Bokutoh Hospital, Tokyo, Japan

4 Department of Gastroenterology and Hepatology, Kitano Hospital, Tazuke Kofukai Medical Research Institute, Osaka, Japan

5 Department of Gastroenterology, Graduate School of Medicine, The University of Tokyo, Tokyo, Japan

6 Department of Gastroenterology, Nippon Medical School, Graduate School of Medicine, Tokyo, Japan

7 Department of Gastroenterology, St. Luke's International University, Tokyo, Japan

8 Department of Gastroenterology, Hiroshima City Asa Citizens Hospital, Hiroshima, Japan

9 Department of Gastroenterology, Saga Medical Center Koseikan, Saga, Japan 
10 Division of Gastroenterology and Hepatology, Department of Internal Medicine, St Marianna University School of Medicine, Kanagawa, Japan

11 Department of Gastroenterology and Hepatology, Center for Digestive and Liver Diseases, Nara city Hospital, Nara, Japan

12 Department of Gastroenterology, Tokyo Shinagawa Hospital, Tokyo, Japan

13 Department of Endoscopy, Nagoya University Hospital, Aichi, Japan

14 Department of Gastroenterology, National Hospital Organization Kyoto Medical Center, Kyoto, Japan

15 Department of Gastroenterology, Tokyo Metropolitan Cancer and Infectious Diseases Center Komagome Hospital, Tokyo, Japan

16 Department of Gastroenterology, Oita University, Oita, Japan

17 Department of Gastroenterology, Fukuoka University Chikushi Hospital, Fukuoka, Japan

18 Department of Gastroenterology, Chiba Hokusoh Hospital, Nippon Medical School, Chiba, Japan

19 Department of Gastroenterology, Japanese Red Cross Shizuoka Hospital, Shizuoka, Japan

20 Division of Endoscopy and Ultrasonography, Department of Clinical Pathology and Laboratory Medicine, Kawasaki Medical School General Medical Center, Okayama, Japan

21 Division of Gastroenterology, Graduate School of Medical and Dental Sciences, Niigata University, Niigata, Japan

22 Department of Gastroenterology and Hepatology, Center for Digestive Disease and Division of Endoscopy, University of Miyazaki Hospital, Miyazaki, Japan

23 Department of Gastroenterology, University of Tsukuba, Ibaraki, Japan

24 Division of Endoscopic Center, University of Tsukuba Hospital, Ibaraki Japan

25 Department of Gastroenterology, Toranomon Hospital, Tokyo, Japan

26 Emergency and Critical Care Center, Saiseikai Yokohamashi Tobu Hospital, Kanagawa, Japan

27 Department of Gastroenterology, Naha City Hospital, Okinawa, Japan

28 Department of Internal Medicine, Tokyo Saiseikai Central Hospital, Tokyo, Japan

29 Department of Gastroenterology, Shuto General Hospital, Yamaguchi, Japan 
30 Division of Endoscopy, Hirosaki University Hospital, Aomori, Japan

31 Department of Gastroenterology and Hepatology, Graduate School of Medical Sciences, Kumamoto University, Kumamoto, Japan

32 Department of Gastroenterology and Hepatology, National Hospital Organization Fukuokahigashi Medical Center, Fukuoka, Japan

33 Department of Medicine and Clinical Science, Graduate School of Medical Sciences, Kyushu University, Fukuoka, Japan

34 Department of Gastroenterology, Fukushima Medical University, Fukushima, Japan

35 Division of Gastroenterology, Department of Internal Medicine, Iwate Medical University, Iwate, Japan

36 Department of Internal Medicine, National Defense Medical College, Saitama, Japan 37 Division of Endoscopy and Ultrasonography, Department of Clinical Pathology and Laboratory Medicine, Kawasaki Medical School, Okayama, Japan

38 Department of Gastroenterology and Hepatology, Suita Municipal Hospital, Osaka, Japan

39 Department of Endoscopy, University of the Ryukyus Hospital, Okinawa, Japan

40 Department of Gastroenterology, National Hospital Organization Kyushu Medical Center, Fukuoka, Japan

41 Department of Gastroenterological Endoscopy, Fukuoka University Hospital, Fukuoka, Japan

42 Department of Gastroenterology, Kitasato University, School of Medicine, Kanagawa, Japan

43 Department of Gastroenterology and Neurology, Akita University Graduate School of Medicine, Akita, Japan

44 Digestive and Lifestyle Diseases, Kagoshima University Graduate School of Medical and Dental Sciences, Kagoshima, Japan

45 Department of Gastroenterology and Hepatology, Tokyo Medical University, Tokyo, Japan

46 Department of Gastroenterology and Hepatology, National Center for Global Health and Medicine, Kohnodai Hospital, Chiba, Japan 
Running Head: bleeding etiologies and outcomes

\begin{abstract}
Abbreviations: ALGIB, acute lower gastrointestinal bleeding; CCI, Charlson comorbidity index; CRP, C-reactive protein; CT, computer tomography; DOACs, direct oral anticoagulants; GIB, gastrointestinal bleeding; HSE, hypertonic saline epinephrine; INR, international normalized ratio; IQR, inter quartile range; IVR, interventional radiology; JP, Japan; LGIB, lower gastrointestinal bleeding; LOS, length of hospital stay; NSAIDs, non-steroidal anti-inflammatory drugs; RCTs, randomized controlled trials; SRH, stigmata of recent hemorrhage; UGIB, upper gastrointestinal bleeding; UK, united kingdom; US, united states
\end{abstract}

*Correspondence: Naoyoshi Nagata, MD, PhD.

Department of Gastroenterological Endoscopy, Tokyo Medical University, 6-7-1

Nishishinjuku, Shinjuku-ku, Tokyo 160-0023, Japan

E-mail: nnagata_ncgm@yahoo.co.jp 


\begin{abstract}
Background: The value of endoscopy for acute lower GI bleeding (ALGIB) remains unclear, given few large cohort studies. We aim to provide detailed clinical data for ALGIB management and to identify patients at risk for adverse outcomes based on endoscopic diagnosis.
\end{abstract}

Methods: We conducted a multicenter, retrospective cohort study, named CODE BLUE J-Study, in 49 hospitals throughout Japan and studied 10,342 cases admitted for outpatient-onset of acute hematochezia.

Results: Cases were mostly elderly, with $29.5 \%$ hemodynamic instability and $60.1 \%$ comorbidity. $69.1 \%$ and $87.7 \%$ of cases underwent CT and colonoscopy, respectively. Diagnostic yield of colonoscopy reached $94.9 \%$, revealing 48 etiologies, most frequently diverticular bleeding. During hospitalization, the endoscopic therapy rate was $32.7 \%$, mostly using clipping and band ligation. IVR and surgery were infrequently performed, for $2.1 \%$ and $1.4 \%$. In-hospital rebleeding and death occurred in $15.2 \%$ and 0.9\%. Diverticular bleeding cases had higher rates of hemodynamic instability, rebleeding, endoscopic therapy, IVR, and transfusion, but lower rates of death and surgery than other etiologies. Small bowel bleeding cases had significantly higher rates of surgery, IVR, and transfusion than other etiologies. Malignancy or upper GIB cases had significantly higher rates of thromboembolism and death than other etiologies. Etiologies that have favorable outcomes were ischemic colitis, infectious colitis, and post-endoscopy bleeding.

Conclusions: Large-scale data of patients with acute hematochezia revealed high proportions of colonoscopy and $\mathrm{CT}$, resulting in high endoscopic therapy rates. We highlight the importance of colonoscopy in detecting accurate bleeding etiologies that stratify patients at high or low risk of adverse outcomes.

Key words: acute lower gastrointestinal hemorrhage; colonic diverticular bleeding; endoscopic diagnosis; endoscopic therapy; mortality 


\section{Introduction}

Acute lower gastrointestinal bleeding (ALGIB) manifests as relatively mild hematochezia (maroon or red blood passed through the rectum) progressing to massive hemorrhage with shock[1-3]. Approximately 30-50\% of adults with ALGIB will progress to severe bleeding[4-7], and bleeding can recur frequently, requiring reexamination, re-hospitalization, and repeated transfusion[1-7]. Moreover, ALGIB episodes have been shown to increase the risk of subsequent thromboembolism and death, regardless of antithrombotic drug use[8]. Under these conditions, ALGIB presents a significant economic burden[9]. Unlike upper GIB (UGIB), which can be treated by anti-acid therapy, there are no effective therapies for preventing ALGIB and its recurrence[1]. Therefore, approaches to initial management, diagnosis, intervention, and follow-up of ALGIB remain uncertain, and there is likely to be considerable variation in clinical practice. Although the rate of UGIB has been decreasing rapidly over the past 10 years, LGIB has increased slightly[10,11], which also applies to Japan[12]. Therefore, evidence-building for the management of ALGIB will grow increasingly important.

Although a few guidelines for ALGIB exist[1-3], most of statements are supported by low to moderate quality evidence because of challenges in performing randomized controlled trials (RCTs) in the ALGIB setting[13]. Even if a RCT can be performed, it may differ from clinical practice because elderly patients with comorbid conditions are frequently excluded from RCTs[14,15]. We therefore consider it important to clarify the factors associated with outcomes from observational studies without excluding patients. However, an adequate sample size is required to analyze the outcome and its associated factors because small sample size may result in insufficient power and type 2 error[16,17]. To date, compared to UGIB, there are few large studies using real-world clinical data, especially more than 1,000 ALGIB cases. Although one large UK study showed detailed clinical courses in ALGIB[18], it could not accurately identify bleeding etiologies by endoscopy, or assess their relevant outcomes. Adverse clinical outcomes may substantially differ among etiologies; if so, this confirms the value of colonoscopy, as recommended in the guidelines[1,3].

To address these issues, we have conducted a multi-center observational cohort study throughout Japan, collecting data from over 10,000 cases of acute hematochezia and 
extensively examining ALGIB etiologies. We aim to provide detailed clinical data for ALGIB management, to identify patients at risk for adverse outcomes by bleeding etiology, and to compare clinical data to the UK study.

\section{Methods}

\section{Study design, settings, and participants}

We conducted a multicenter, retrospective cohort study in emergency hospitals throughout Japan. To collect real-world clinical data, we invited the participation of gastroenterology physicians who were directly involved in the treatment of hematochezia. A total of 49 facilities located in 25 prefectures, from Okinawa prefecture in the south to Aomori prefecture in the north, wanted to participate. Representative physicians in each hospital agreed to a study of detailed clinical data of patients with acute hematochezia, named CODE BLUE-J Study (COlonic DivErticular Bleeding Leaders Update Evidence from multicenter Japanese Study). The ethics committees and the institutional review boards approved conducting this study with the opt-out method in all 49 participating hospitals (Supplementary Table 1). Patients and/or the public were not involved in the design, or conduct, or reporting, or dissemination plans of this research.

We selected patients admitted for acute hematochezia from January 2010 to December 2019. We included patients aged $\geq 20$ years at the onset of hematochezia regardless of presence of tarry stools, diarrhea, abdominal pain, or fever. We excluded patients after elimination of hematochezia, those who were hospitalized for examination for anemia, whose onset of hematochezia was in hospital, or for whom data collection was not possible due to insufficient information on medical records. A total of 11,035 patients were included, and all data were re-evaluated rigorously by secretariat's institution (Tokyo Medical University); then 693 patients met the exclusion criteria. Ultimately, 10,342 cases emergently admitted for outpatient onset of acute, continuous, or frequent hematochezia were evaluated.

\section{Data collection}

Before collecting data, we conducted research meetings three times with representatives from the 49 participating hospitals on the content and definition of survey items. At the 
research meetings, it was agreed to aim for the registration of at least 100 cases from each institution. The survey items were prepared using Excel sheets formatted to define each clinical factor and data entry rule, and sent to each participating institution. To prevent data omissions or entry errors, and to reduce missing values, we used the datavalidation rules in Excel to input the values and unknowns for the categorical variables (e,g, diabetes mellitus, 0, 1, unknown), and free input for the continuous variables (Supplementary Table 2). At each hospital, data were collected from electric endoscopic records and medical records, and input into an Excel sheet. The sheet was sent to the secretariat's facility (Tokyo Medical University). This facility evaluated omissions and errors (e.g., admission or endoscopy date, data error value) in the input values for the data sent from each hospital (Supplementary Table 2). The data to be corrected were communicated by the input physician(s) of each institution with detailed comments. Such communication was conducted more than three times per hospital with the use of Excel sheets by e-mail.

\section{Variables and outcomes}

Detailed clinical data on patient characteristics and management of hematochezia during hospitalization and after discharge were assessed. As for clinical data, 219 survey items were considered essential (Supplementary Table 2), and 49 items were optional. Baseline characteristics consisted of 75 items, including presenting symptoms, vital signs, blood sample data, past histories, comorbidities, and drug intake within 30 days of admission (Supplementary Table 2). We evaluated 19 comorbidities with the Charlson comorbidity index (CCI)[19], which has been validated and commonly used for GIB research[6,8,18]. Moreover, comorbidities of hypertension and dyslipidemia, not included in CCI, were also collected. During hospitalization, information of CT and endoscopic diagnosis consisting of 80 items (e.g., stigmata of recent hemorrhage (SRH) on endoscopy, etiology of bleeding) was collected. We also evaluated procedures consisting of 41 items, such as type of endoscopic therapy, IVR, and surgery (Supplementary Table 2). Because patients may have received two different or identical procedures during hospitalization due to events after examination and treatment, we evaluated for the procedure items twice. Final diagnosis was made mainly by initial and second endoscopy. Small bowel endoscopy, capsule endoscopy, and upper 
GI endoscopy were performed at the discretion of each institution based on symptoms and tests. Clinical outcomes, consisting of 23 items, included rebleeding, thromboembolism, and mortality (Supplementary Table 2). Dates of occurrence of outcomes were evaluated during hospitalization and after discharge. After discharge, we followed up patients from the index date to the occurrence of any clinical outcomes, and censored patients at the time of the last visit, end of follow-up, or death. In the survival analysis, the endpoint was death, and data were censored as of the time of the last visit, or the end of follow-up. Rebleeding and second rebleeding were evaluated and defined as significant amounts of fresh, bloody or wine-colored stools after admission[6,8,18]. We defined a thromboembolic event as the development of cardiovascular events, cerebrovascular events, pulmonary embolism, or deep vein thrombosis[8]. The diagnosis of thromboembolism was based on typical symptoms, with imaging modalities including CT, magnetic resonance imaging, coronary angiography, ventilation-perfusion scan, ultrasonography, or electrocardiography[8]. Date and cause of death were ascertained from death certificates and medical record reviews[8]. Cause of death was additionally determined from laboratory tests, multiple imaging modalities, or autopsy[8]. Secondary outcomes were blood transfusion during hospital stay and prolonged length of hospital stay (LOS).

\section{Statistical methods}

Descriptive statistics, reported as number and percentage, or median and inter quartile range (IQR) are used to describe patient characteristics, procedures, and clinical outcomes. To compare clinical data between two groups, we used the chi-square test or Fisher's exact test for categorical variables, as appropriate. For the analysis of the association between bleeding etiologies and outcomes, etiologies that have $>50$ cases were included. P-values less than 0.05 were considered significant. All statistical analysis was performed using STATA version 14 software (StataCorp, College Station, TX).

\section{Results}

\section{Baseline characteristics}

The median number of ambulances in the 49 participating hospitals was 5,859, and 24/7 
colonoscopy was available in all institutions (Table 1). The median age was 74 years, with $61.1 \%$ male. About half of patients were current drinkers $(46.3 \%)$ or current or ever smokers (48.8\%). Hemodynamic instability rate was $29.5 \%$. All patients presented with hematochezia, with additional existing symptoms of $16.1 \%$ abdominal pain, $6.4 \%$ fever, and $9.9 \%$ diarrhea. Overall, $30 \%$ of patients had prior histories of acute LGIB. $60.1 \%$ of patients had a CCI $\geq 1$, and the most common comorbidities were hypertension (56.5\%), dyslipidemia (27.3\%), and diabetes (18.7\%). Median laboratory values were 7,150 (/ul) white blood cells, $11.4(\mathrm{~g} / \mathrm{dl})$ hemoglobin, and $3.7(\mathrm{~g} / \mathrm{dl})$ albumin. At presentation, drug administration rates were $11.4 \%$ NSAIDs, $20.0 \%$ low-dose aspirin, $9.8 \%$ thienopyridine, $6.8 \%$ warfarin, $6.0 \%$ DOACs, $2.7 \%$ acetaminophen, and $5.6 \%$ corticosteroids. $6.1 \%$ of patients took dual antiplatelet therapy.

\section{CT diagnosis and endoscopic diagnosis}

CT of the abdomen/pelvis was undertaken in $69.1 \%$ of all cases, with median timing of 1 hour of arriving at the hospital (Table 2). Of these, $73.3 \%$ undertook contrast enhanced CT, and extravasation findings on CT were identified in 22.0\%. Among locations, the ascending colon (10.4\%) was most commonly identified in extravasation on CT, more than twice as often as the sigmoid colon (4.3\%).

Initial colonoscopy was undertaken in $87.7 \%$ of all cases, with median timing of 16 hours of arrival. SRH on endoscopy was identified in $30.9 \%$ of cases, with $16.4 \%$ exhibiting active bleeding, $5.9 \%$ visible vessels, and $9.2 \%$ adherent clots. Similar to CT extravasation, the ascending colon (12.9\%) was the most frequent site of SRH identification, again almost twice as often as the sigmoid colon (7.0\%). A total of $59.2 \%$ $(6,117 / 10,342)$ of patients underwent both endoscopy and CT for further investigation of the source of bleeding, and only $2.4 \%(244 / 10,342)$ of patients who did not undergo colonoscopy had no CT scan. $19.2 \%$ of patients underwent a repeat colonoscopy, with median timing of 53 hours of arriving at the hospital, mainly due to rebleeding. Diagnostic yield of initial and second colonoscopy reached 94.9\%, and 22 bleedingsource categories, covering 48 diseases, were found (Table 2). The most common final diagnosis was colonic diverticular bleeding (63.6\%), followed by ischemic colitis $(9.1 \%)$, post-endoscopic procedure bleeding $(4.5 \%)$, and rectal ulcers $(2.5 \%)$. Bleeding sources other than colon, rectum, and anus were also observed, such as small bowel 
bleeding (2.4\%) and upper GIB (1.5\%). The rate of each etiology in the final diagnosis differed slightly compared to the initial endoscopic diagnosis (Supplementary Table 3); note especially the decreased rate of unknown cases, and increased definite diverticular bleeding.

\section{Endoscopic therapy and other procedures}

To identify the source of bleeding, multiple procedures were often used during periendoscopic procedures: bowel prep with PEG for $66.4 \%$ of patients, enema for $19.1 \%$, endoscopic cap for $72.1 \%$, and waterjet scope for $77.0 \%$ (Table 3). Endoscopic therapy was performed in $30.7 \%$ of patients undergoing endoscopy, mostly clipping $(63.8 \%)$, followed by band ligation (24.2\%), coagulation (8.2\%), snare ligation (3.9\%), and hypertonic saline-epinephrine (HSE) (1.8\%). The success rate of endoscopic therapy was $95.7 \%$, and failure of hemostasis was $4.4 \%$. When initial endoscopic treatment failed, clipping (63.6\%) was the most commonly used follow-up technique. Identified post-endoscopy complications were $0.1 \%$ perforation and $0.03 \%$ diverticulitis. IVR and surgery were performed for $1.4 \%$, and $1.0 \%$, respectively. Secondary endoscopic therapy was performed in $39.5 \%$ of patients undergoing repeat colonoscopy (Supplementary Table 4). The treatment rate for rebleeding was conservative therapy for $53.1 \%$, endoscopic therapy for $40.6 \%$, IVR for $3.6 \%$, and surgery for $1.7 \%$ (Supplementary Table 4). The treatment rate for second rebleeding was conservative therapy for $44.8 \%$, endoscopic therapy for $42.1 \%$, IVR for $10.0 \%$, and surgery for $3.7 \%$ (Supplementary Table 5). The procedure rates of IVR and surgery in second rebleeding were significantly $(\mathrm{p}<0.01)$ higher than for first rebleeding. Overall procedure rates during hospitalization were endoscopic therapy for $32.7 \%$, IVR for $2.1 \%$, and surgery for $1.4 \%$ (Table 3).

\section{Clinical outcomes}

In-hospital rebleeding was identified in $15.2 \%$ of patients: $10.8 \%$ with one episode of rebleeding, $4.4 \%$ with two episodes (Table 4). After discharge, rebleeding developed in 25.6\%: $22.9 \%$ had 1-4 episodes of rebleeding; $1.7 \%$ had 5-9 episodes; and $1.0 \%$ had $\geq$ 10 episodes. Thromboembolic events occurred in $0.6 \%$ of patients, including acute coronary syndrome in $0.2 \%$, cerebrovascular disease in $0.3 \%$ and pulmonary 
embolism/deep vein thrombosis in $0.2 \%$. In-hospital mortality was $0.9 \%$, mainly due to worsening comorbidities and non-bleeding-related deaths. Only $13 \%$ of deaths were directly related to GI bleeding. Out-of-hospital mortality was $6.8 \%$ with a median follow-up of 239 days after discharge. Blood transfusion was administered in $29.8 \%$ of patients, with a median number of 4 units. The median length of stay was 7 days.

\section{Association between clinical outcomes and bleeding etiologies}

The proportions of clinical outcomes differed according to bleeding etiologies (Table 5). Etiologies that were more likely to have adverse outcomes included diverticular bleeding, malignancy, rectal ulcer, small bowel bleeding, or UGIB. For example, patients with diverticular bleeding had significantly higher rates of hemodynamic instability, 30-day-rebleeding, need of endoscopic therapy, IVR, and transfusion, but lower rates of death and surgical need than other etiologies. Patients with small bowel bleeding had significantly higher rates of surgery, IVR, and transfusion than other etigologies. Malignancy or UGIB cases had significantly higher rates of thromboembolism and death than those without them, respectively. At presentation, hemodynamic instability was common in $59.7 \%$ of patients with UGIB. In contrast, diseases that have relatively favorable outcomes and may not require intensive care after endoscopy were ischemic colitis, infectious colitis, and post-endoscopy bleeding. For instance, patients with ischemic colitis showed significantly lower rates of hemodynamic status, 30-day-rebleeding, death, and need of endoscopic therapy, IVR, and transfusion than those other etiologies.

\section{Comparison of clinical data between Japan (JP) and the UK study}

Differences of clinical data between JP and the UK are shown in Supplementary Table

7. In JP, no missing values in data collection regarding diagnosis, procedures, or outcomes were noted (Supplementary Table 2), whereas many of the aforementioned items contained missing values in the UK study, such as data for endoscopic therapy in $5.6 \%(141 / 2,528)$, rebleeding in $5.0 \%(126 / 2,528)$, and length of stay in $6.2 \%$ (156/2258). Of baseline characteristics, comorbidity index rates of 1 and $\geq 2$ scores and median age were similar in both data sets. However, compared to UK data, JP data had

higher proportions of age $\geq 60 \mathrm{y}$, male, presenting tarry stools, hemoglobin value $\leq 7.0$ 
(g/dl), past history of LGIB, NSAID use, and lower proportions of abdominal pain, lowdose aspirin, and warfarin. In diagnosis, compared to the UK, JP had proportions three times higher or more of performing CT (69.0\% vs $20.1 \%)$, initial colonoscopy $(87.8 \%$ vs $29.3 \%)$, and repeat colonoscopy (19.3\% vs $1.7 \%)$. The most common source of bleeding was diverticular bleeding in both groups, followed in the UK by hemorrhoids in $12 \%$ and malignancies in $6 \%$, and in JP by ischemic colitis in $9 \%$ and procedurerelated bleeding in $4.4 \%$. Notably, the unknown bleeding etiology rate was four times lower in JP than the UK (5.2\% vs 22.8\%). Among procedures, the endoscopic therapy rate was more than 10 times higher in JP than the UK (32.7\% vs $2.3 \%)$, whereas the rates of IVR and surgical need were not significantly different between the two groups. In outcomes, no significant differences were noted in the rate of in-hospital rebleeding, but overall transfusion rate and transfusion received $\geq 4$ units were significantly higher in JP than the UK. Occurrence of acute coronary syndrome and cerebrovascular disease were not significant in either group. In-hospital mortality was more than three times higher in the UK than JP (3.4\% vs $0.9 \%)$. Median length of stay was longer in JP than in the UK.

\section{Discussion}

In this study, we focused on data from patients with acute hematochezia, rather than colorectal/anal bleeding (LGIB), because the details of bleeding sources remain unclear without endoscopy. We constructed an unprecedentedly large-scale data set and provided information of baseline characteristics, etiologies, interventions, and clinical outcomes. In particular, the high endoscopic rates in JP have revealed a much more detailed and accurate picture of bleeding sources, resulting in performance of endoscopic therapy in $1 / 3$ of all cases, much higher than in previous studies[6,18]. Moreover, bleeding etiologies allowed identification of patients at risk for adverse outcomes. These two findings suggest the importance of accurate diagnosis by colonoscopy, as described in guidelines[1,3]. Finally, comparison of large-scale data in the UK and JP revealed a higher rate of in-hospital mortality in the UK[18], but a higher rate of transfusion in JP, despite similar rates of in-hospital rebleeding and thromboembolism.

Compared to the UK data[18], JP had a three times higher proportion of CT, initial 
colonoscopy, and repeat colonoscopy, enabling accurate identification of etiologies of acute hematochezia. The diagnostic yield of final diagnosis based on initial and secondary endoscopies reached $94.9 \%$, contributing to identification of 48 diseases, as bleeding etiologies. Only 5\% of etiologies remained unknown, a lower rate than in the US at $9 \%[6]$, the UK at 23\%[18], and Spain at 18\%[20]. This is partly because endoscopy is readily accessible in JP hospitals[3]. The most common etiology was diverticular bleeding, at 64\%, which is consistent with earlier ALGIB reports[18,20], regardless of different proportions of $30 \%(75 / 252)$ in the US[6], 26\% $(668 / 2,528)$ in the UK[18], and 39\% (163/415) in Spain[20]. The top 3 diagnoses other than diverticulosis were ischemic colitis, post-endoscopy bleeding, and rectal ulcer in JP, similar to hemorrhoids, ischemic colitis, and post-endoscopic bleeding in the US[6], but not to hemorrhoids, undetermined colitis, and malignancies in the UK[18]. The differences in order and proportions of etiologies between countries are probably due to the difference in the rates of colonoscopy received and in hospital departments managed (e.g., surgery department in the UK vs gastroenterology in JP)[18].

Among bleeding locations, the ascending colon was most commonly identified in SRH on colonoscopy and extravasation on CT, more than twice as often as the sigmoid colon, suggesting the importance of total colonoscopy. If only sigmoidoscopy were performed, $89 \%$ of the overall SRH, and endoscopically treatable lesions would have been missed. Compared to prior studies showing $8 \%$ to $26 \% \mathrm{SRH}[15,21,22]$, we found a high rate of $31 \%$, due to the high use of bowel preparation in $84 \%$ before endoscopy and of devices to be attached to the endoscope (e.g., cap, 73\% and waterjet, 77\%) during endoscopy (Table 3). The high SRH identification rate enabled endoscopic treatment in 33\%, which is more than 10 times higher than in the UK[18].

Among endoscopic therapies, clipping is a common worldwide treatment, also the most common in JP (64\%). In contrast, HSE and coagulation, commonly used in the US[23], were used in $10 \%$ or less of cases in JP. Treatment in JP is characterized by the use of novel therapies such as band ligation and snare ligation, which have been scarcely reported in the US or UK[23,24]. In recent years, the evidence that band ligation is more effective in preventing recurrence than clipping has been accumulating[23,24], so it may become the mainstream treatment for ALGIB. The rate of IVR or surgery in JP was less than $5 \%$, which was similar to the UK[18]. Both treatments were performed 
more frequently at second rebleeding than first rebleeding, suggesting that physicians are prone to performing endoscopy first, even if extravasation on CT is positive, and to choosing IVR/surgery when uncontrolled bleeding is present, which is in compliance with JP and US guidelines[1,3], but not UK guidelines[2].

In-hospital mortality was more than three times higher in the UK than in JP regardless of a similar rate of $\geq 2$ comorbidity score[18], and higher rates of being $60 \mathrm{y}$ or older or having hemoglobin $<7$ in JP. This was probably because the UK database listed malignancy more than 3 times as often as JP. Another reason was that the rate of endoscopy and endoscopic treatment was much higher in JP than in the UK, which enhances control of continuous or massive or recurrent bleeding. Uncontrolled LGIB episodes have been suggested to increase the risk of death from worsening comorbidities, although bleeding is not the direct cause of death[8]. The reason the length of stay was longer in JP than the UK is that JP tends to monitor the progress of ALGIB patients carefully since they are administered fasting intravenous drip first, with the diet gradually changing to a normal diet[15,25]. In fact, prior LGIB reports in JP show a median hospital stay of 7 days[15,25].

Guidelines state that the value of the colonoscopy for ALGIB is to identify the bleeding etiology and perform hemostasis if indicated[1,3]. However, in addition to this, we hypothesized that colonoscopy could uncover important factors associated with clinical outcomes. Regrettably, prior ALGIB studies have never evaluated the association between endoscopic diagnoses and outcomes[4-7,26]. Significantly, we found that high-risk etiologies of adverse outcomes were diverticular bleeding, malignancy, rectal ulcer, small bowel bleeding, or UGIB among patients with hematochezia. In contrast, low-risk etiologies were ischemic colitis, infectious colitis, or post-endoscopy bleeding. This indicates that accurate identification of bleeding etiology can stratify patients at risk for adverse outcomes, helping physicians determine whether they should give intensive care, or otherwise recommend prompt discharge after endoscopy. In addition, we associated endoscopic diagnosis with initial characteristics: UGIB is associated with hemodynamic instability, and may be indicative of an UGIB source and warrants an upper endoscopy. Although there was no high quality evidence to support this finding, we confirmed the validity of the UK and US guidelines[1,2].

We recognize limitations to this study. First, this was a retrospective study, leading to 
some missing values in baseline characteristics (e.g., alcohol intake and INR values), potentially a source of bias. However, there were no missing values for diagnosis, procedures, and outcomes in the JP data, and items with missing values and their rates were lower than in the UK prospective study. Second, all participating institutions have relatively large numbers of beds and 24/7 colonoscopy accessible, and it remains unclear whether our results are applicable to non-emergency hospitals with different settings.

In conclusion, we provided useful clinical data for ALGIB management from 10,342 patients with acute hematochezia. Although some data were similar to the UK nationwide data, the Japanese data are characterized by higher rates of endoscopy, CT examination, and lower mortality. A high endoscopic rate detects accurate bleeding etiologies, enabling us to stratify patients at high or low risk of adverse outcomes, emphasizing the high value of colonoscopy.

\section{Collaborators}

CODE BLUE J-study group: full names and affiliations listed in the online

\section{Supplementary Table 1.}

\section{Contributors}

NN was principal investigator of this study. NN designed and conducted the study, interpreted the data, and mainly wrote the paper. KK (Bokuto hospital), AY, AY. JO, TI, TA, NT, YS, TK, NI, TS, MM, AT, KM, KK (Fukuoka University Chikushi Hospital), SF, TU, MF, HS, SS, TN, JH, TF, YK, AM, SK, TM, RG, HF, YF, NG, YT, KN, NM, KN, TK, YS, SF, KK, TM, YK, KM, KW, and MK designed the study, made decisions and definitions of survey items, and interpreted the data. NN and KM performed the statistical analysis. MF, TI, NU, TK, MK provided corrections and advice on the preparation of the paper.

\section{Funding}

This work was partially supported by grants from the Ministry of Health, Labour and Welfare, Japan (grant number: 19HB1003), JSPS KAKENHI Grant (JP17K09365 and 
20K08366), Smoking Research Foundation, Takeda Science Foundation, Grants-in-Aid for Research from the National Center for Global Health and Medicine (29-2001, 292004, 19A1011, 19A1022, 19A-2015, 29-1025, and 30-1020). The funders played no role in the study design, analysis, decision to publish the manuscript.

\section{Competing interests}

None declared.

\section{Acknowledgements}

The authors thank Kazuyo Jo, Shiho Kamimura, Sanae Habu, Akiko Takamatsu, Minako Kajihara, and Kenko Yoshida for their help with the data collection and analysis.

\section{References}

1 Strate LL, Gralnek IM. ACG Clinical Guideline: Management of Patients With Acute Lower Gastrointestinal Bleeding. Am J Gastroenterol 2016;111:459-74.

2 Oakland K, Chadwick G, East JE, et al. Diagnosis and management of acute lower gastrointestinal bleeding: guidelines from the British Society of Gastroenterology. Gut 2019;68:776-89.

3 Nagata N, Ishii N, Manabe N, et al. Guidelines for Colonic Diverticular Bleeding and Colonic Diverticulitis: Japan Gastroenterological Association. Digestion 2019;99:1-26.

4 Oakland K, Jairath V, Uberoi R, et al. Derivation and validation of a novel risk score for safe discharge after acute lower gastrointestinal bleeding: a modelling study. Lancet Gastroenterol Hepatol 2017;2:635-43.

5 Aoki T, Nagata N, Shimbo T, et al. Development and Validation of a Risk Scoring System for Severe Acute Lower Gastrointestinal Bleeding. Clin Gastroenterol Hepatol 2016;14:1562-70. 
6 Strate LL, Orav EJ, Syngal S. Early predictors of severity in acute lower intestinal tract bleeding. Arch Intern Med 2003;163:838-43.

7 Velayos FS, Williamson A, Sousa KH, et al. Early predictors of severe lower gastrointestinal bleeding and adverse outcomes: a prospective study. Clin Gastroenterol Hepatol 2004;2:485-90.

8 Nagata N, Sakurai T, Shimbo T, et al. Acute Severe Gastrointestinal Tract Bleeding Is Associated With an Increased Risk of Thromboembolism and Death. Clin Gastroenterol Hepatol 2017;15:1882-9.

9 Parker DR, Luo X, Jalbert JJ, et al. Impact of upper and lower gastrointestinal blood loss on healthcare utilization and costs: a systematic review. J Med Econ 2011;14:279-87.

10 Lanas A, García-Rodríguez LA, Polo-Tomás M, et al. The changing face of hospitalisation due to gastrointestinal bleeding and perforation. Aliment Pharmacol Ther 2011;33:585-91.

11 Lanas A, García-Rodríguez LA, Polo-Tomás M, et al. Time trends and impact of upper and lower gastrointestinal bleeding and perforation in clinical practice. Am J Gastroenterol 2009;104:1633-41.

12 Nagata N, Niikura R, Aoki T, et al. Increase in colonic diverticulosis and diverticular hemorrhage in an aging society: lessons from a 9-year colonoscopic study of 28,192 patients in Japan. Int J Colorectal Dis 2014;29:379-85.

13 Laine L, Shah A. Randomized trial of urgent vs. elective colonoscopy in patients hospitalized with lower GI bleeding. Am J Gastroenterol 2010;105:2636-41; quiz 2642.

14 Van Spall HGC, Toren A, Kiss A, et al. Eligibility criteria of randomized controlled trials published in high-impact general medical journals: a systematic sampling review. JAMA 2007;297:1233-40. 
15 Niikura R, Nagata N, Yamada A, et al. Efficacy and Safety of Early vs Elective Colonoscopy for Acute Lower Gastrointestinal Bleeding. Gastroenterology 2020;158:168-75.

16 Altman DG. Statistics and ethics in medical research: III How large a sample? $\mathrm{Br}$ Med J 1980;281:1336-8.

17 Halpern SD, Karlawish JHT, Berlin JA. The continuing unethical conduct of underpowered clinical trials. JAMA 2002;288:358-62.

18 Oakland K, Guy R, Uberoi R, et al. Acute lower GI bleeding in the UK: patient characteristics, interventions and outcomes in the first nationwide audit. Gut 2018;67:654-62.

19 Charlson ME, Pompei P, Ales KL, et al. A new method of classifying prognostic comorbidity in longitudinal studies: development and validation. J Chronic Dis 1987;40:373-83.

20 Lanas Á, Carrera-Lasfuentes P, Arguedas Y, et al. Risk of upper and lower gastrointestinal bleeding in patients taking nonsteroidal anti-inflammatory drugs, antiplatelet agents, or anticoagulants. Clin Gastroenterol Hepatol 2015;13:906-12.

21 Strate LL, Syngal S. Timing of colonoscopy: impact on length of hospital stay in patients with acute lower intestinal bleeding. Am J Gastroenterol 2003;98:317-22.

22 Nagata N, Niikura R, Sakurai T, et al. Safety and Effectiveness of Early Colonoscopy in Management of Acute Lower Gastrointestinal Bleeding on the Basis of Propensity Score Matching Analysis. Clin Gastroenterol Hepatol 2016;14:558-64.

23 Ishii N, Omata F, Nagata N, et al. Effectiveness of endoscopic treatments for colonic diverticular bleeding. Gastrointest Endosc 2018;87:58-66.

24 Nagata N, Niikura R, Ishii N, et al. Cumulative Evidence for Reducing Recurrence of Colonic Diverticular Bleeding Using Endoscopic Clipping versus Band 
medRxiv preprint doi: https://doi.org/10.1101/2021.01.18.21250035; this version posted January 20, 2021. The copyright holder for this preprint (which was not certified by peer review) is the author/funder, who has granted medRxiv a license to display the preprint in perpetuity. It is made available under a CC-BY-NC-ND 4.0 International license.

Ligation: Systematic Review and Meta-analysis. J Gastroenterol Hepatol Published Online First: 8 December 2020. doi:10.1111/jgh.15370

25 Nagata N, Niikura R, Shimbo T, et al. High-dose barium impaction therapy for the recurrence of colonic diverticular bleeding: a randomized controlled trial. Ann Surg 2015;261:269-75.

26 Sengupta N, Tapper EB. Derivation and Internal Validation of a Clinical Prediction Tool for 30-Day Mortality in Lower Gastrointestinal Bleeding. Am J Med 2017;130:601.e1-601. 
Table 1 Baseline characteristics

\begin{tabular}{|c|c|c|c|}
\hline Factor & Value & $\begin{array}{l}\text { Data } \\
\text { available } \\
\text { for } \\
\text { analysis }\end{array}$ & $\begin{array}{l}\text { Missing } \\
\text { value }\end{array}$ \\
\hline Outpatient onset & $10,342(100)$ & 10,342 & 0 \\
\hline Number of ambulances & $5,859(3,854-9,246)$ & 49 & 0 \\
\hline 24/7 colonoscopy access & $49(100)$ & 49 & 0 \\
\hline Age & $74(63-82)$ & 10,342 & 0 \\
\hline Age $\geq 60 y$ & $8,327(80.5)$ & 10,342 & 0 \\
\hline Male & $6,317(61.1)$ & 10,342 & 0 \\
\hline Blood type, $\mathrm{O}$ & $3,312(33.7)$ & 9,841 & $501(4.8)$ \\
\hline Blood type, A & $3,644(37.0)$ & 9,841 & $501(4.8)$ \\
\hline Blood type, B & $2,021(20.5)$ & 9,841 & $501(4.8)$ \\
\hline Blood type, $\mathrm{AB}$ & $864(8.8)$ & 9,841 & $501(4.8)$ \\
\hline Height, $\mathrm{cm}$ & $160(152-167)$ & 9,789 & $553(5.3)$ \\
\hline Body weight, kg & $57.3(48.9-66.4)$ & 9,921 & $421(4.1)$ \\
\hline BMI & $22.5(20.1-24.9)$ & 9,715 & $627(6.1)$ \\
\hline $\mathrm{BMI}>25$ & $2,381(24.5)$ & 9,715 & $627(6.1)$ \\
\hline Alcohol, current drinker & $4,130(46.3)$ & 8,918 & $1424(13.8)$ \\
\hline Smoking, never & $4,702(51.2)$ & 9,179 & $1163(11.2)$ \\
\hline Smoking, current & $1,661(18.1)$ & 9,179 & $1163(11.2)$ \\
\hline Smoking, ever & $2,816(30.7)$ & 9,179 & $1163(11.2)$ \\
\hline Performance status, 1 & $8,976(87.8)$ & 10,220 & $122(1.2)$ \\
\hline Performance status, 2 & $694(6.8)$ & 10,220 & $122(1.2)$ \\
\hline Performance status, 3 & $304(3.0)$ & 10,220 & $122(1.2)$ \\
\hline Performance status, 4 & $244(2.4)$ & 10,220 & $122(1.2)$ \\
\hline Blood pressure $(\mathrm{mmHg})$ & $127(111-145)$ & 10,161 & $181(1.8)$ \\
\hline Heart rate (/minutes) & $83(73-96)$ & 10,140 & $202(2)$ \\
\hline Syncope/ loss of consciousness & $668(6.5)$ & 10,324 & $18(0.2)$ \\
\hline Hemodynamic instability* & $3,046(29.5)$ & 10,342 & 0 \\
\hline Abdominal pain & $1,664(16.1)$ & 10,323 & $19(0.2)$ \\
\hline Fever & $660(6.4)$ & 10,320 & $22(0.2)$ \\
\hline Diarrhea & $1,016(9.9)$ & 10,307 & $35(0.3)$ \\
\hline Hematochezia & $10,342(100)$ & 10,342 & 0 \\
\hline Tarry stools & $593(5.8)$ & 10,321 & $21(0.2)$ \\
\hline Hemoglobin (g/dl) & $11.4(9.3-13.1)$ & 10,334 & $8(0.1)$ \\
\hline Hemoglobin $\leq 7.0(\mathrm{~g} / \mathrm{dl})$ & $798(7.7)$ & 10,342 & 0 \\
\hline White blood cells (/ul) & $7,150(5,600-9,300)$ & 10,335 & $7(0.1)$ \\
\hline Platelet count (/ul) & $20.8(16.8-25.3)$ & 10,331 & $11(0.1)$ \\
\hline Albumin $(\mathrm{g} / \mathrm{dl})$ & $3.7(3.3-4.1)$ & 9,857 & $485(4.7)$ \\
\hline PT-INR & $1.0(1.0-1.0)$ & 9,012 & $1330(12.9)$ \\
\hline Hematocrit (\%) & $34.2(28.4-39)$ & 10,322 & $20(0.2)$ \\
\hline Blood urea nitrogen $(\mathrm{mg} / \mathrm{dl})$ & $19.0(14.7-25.0)$ & 10,273 & $69(0.7)$ \\
\hline Creatinine $(\mathrm{mg} / \mathrm{dl})$ & $0.8(0.7-1.1)$ & 10,269 & $73(0.7)$ \\
\hline
\end{tabular}




\begin{tabular}{|c|c|c|c|}
\hline $\mathrm{CRP}(\mathrm{mg} / \mathrm{dl})$ & $0.2(0.1-0.5)$ & 10,067 & $275(2.7)$ \\
\hline History of bowel resection & $752(7.3)$ & 10,340 & $2(0.01)$ \\
\hline History of chemotherapy & $338(3.3)$ & 10,319 & $23(0.2)$ \\
\hline History of radiation therapy & $241(2.3)$ & 10,325 & $17(0.2)$ \\
\hline Past history LGIB & $3,090(30.0)$ & 10,342 & 0 \\
\hline History of angiectasia & $72(0.7)$ & 10,341 & $1(0.01)$ \\
\hline History of IBD & $233(2.3)$ & 10,341 & $1(0.01)$ \\
\hline History of diverticular bleeding & $2,603(25.2)$ & 10,334 & $8(0.1)$ \\
\hline History of ischemic colitis & $223(2.2)$ & 10,341 & $1(0.01)$ \\
\hline Charlson Comorbidity Index, 0 & $4,124(39.9)$ & 10,342 & 0 \\
\hline Charlson Comorbidity Index, 1 & $2,431(23.5)$ & 10,342 & 0 \\
\hline Charlson Comorbidity Index, $\geq 2$ & $3,787(36.6)$ & 10,342 & 0 \\
\hline Diabetes mellitus, uncomplicated & $1,933(18.7)$ & 10,342 & 0 \\
\hline Diabetes mellitus, end-organ damage & $350(3.4)$ & 10,342 & 0 \\
\hline Hemiplegia & $278(2.7)$ & 10,334 & $8(0.1)$ \\
\hline Cerebral vascular accident or TIA & $1,475(14.3)$ & 10,340 & $2(0.02)$ \\
\hline COPD & $315(3.1)$ & 10,342 & 0 \\
\hline Dementia & $565(5.5)$ & 10,334 & $8(0.1)$ \\
\hline Connective tissue disease & $418(4.0)$ & 10,342 & 0 \\
\hline Myocardial infarction & $1,660(16.1)$ & 10,342 & 0 \\
\hline Chronic heart failure & $854(8.3)$ & 10,340 & $2(0.02)$ \\
\hline Peptic ulcer disease & $726(7.0)$ & 10,342 & 0 \\
\hline Moderate chronic kidney disease & $1,479(14.3)$ & 10,340 & $2(0.02)$ \\
\hline Severe chronic kidney disease & $326(3.2)$ & 10,342 & 0 \\
\hline Peripheral vascular disease & $421(4.1)$ & 10,342 & 0 \\
\hline Leukemia/ myeloma & $68(0.7)$ & 10,342 & 0 \\
\hline AIDS & $19(0.2)$ & 10,333 & $9(0.1)$ \\
\hline Solid tumor, localized & $1,332(12.9)$ & 10,335 & $7(0.1)$ \\
\hline Solid tumor, metastatic & $254(2.5)$ & 10,342 & 0 \\
\hline Liver disease, mild & $217(2.1)$ & 10,341 & $1(0.01)$ \\
\hline Liver disease, moderate to severe & $207(2.0)$ & 10,341 & $1(0.01)$ \\
\hline Malignant lymphoma & $83(0.8)$ & 10,342 & 0 \\
\hline Hypertension & $5,842(56.5)$ & 10,342 & 0 \\
\hline Dyslipidemia & $2,822(27.3)$ & 10,341 & $1(0.01)$ \\
\hline NSAIDs & $1,177(11.4)$ & 10,342 & 0 \\
\hline NSAIDs (noncoxib) & $929(9.0)$ & 10,342 & 0 \\
\hline COX-2 selective inhibitors & $272(2.6)$ & 10,342 & 0 \\
\hline Low-dose aspirin & $2,056(20.0)$ & 10,342 & 0 \\
\hline Thienopyridine & $1,014(9.8)$ & 10,342 & 0 \\
\hline Cilostazol & $243(2.4)$ & 10,342 & 0 \\
\hline Other antiplatelet drugs & $303(2.9)$ & 10,342 & 0 \\
\hline Number of antiplatelet drugs, 0 & $7,420(71.8)$ & 10,342 & 0 \\
\hline Number of antiplatelet drugs, 1 & $2,262(21.9)$ & 10,342 & 0 \\
\hline Number of antiplatelet drugs, 2 & $626(6.1)$ & 10,342 & 0 \\
\hline
\end{tabular}


medRxiv preprint doi: https://doi.org/10.1101/2021.01.18.21250035; this version posted January 20, 2021. The copyright holder for this preprint

(which was not certified by peer review) is the author/funder, who has granted medRxiv a license to display the preprint in perpetuity.

\begin{abstract}
It is made available under a CC-BY-NC-ND 4.0 International license .
\end{abstract}

\begin{tabular}{|l|l|l|l|}
\hline Number of antiplatelet drugs, 3 & $34(0.3)$ & 10,342 & 0 \\
\hline Warfarin & $705(6.8)$ & 10,342 & 0 \\
\hline DOACs & $615(6.0)$ & 10,342 & 0 \\
\hline Acetaminophen & $277(2.7)$ & 10,342 & 0 \\
\hline Corticosteroid & $579(5.6)$ & 10,342 & 0 \\
\hline
\end{tabular}

Note. *Hemodynamic instability was defined as initial systolic blood pressure < $90 \mathrm{~mm} \mathrm{Hg}$, initial heart rate $\geq 100 / \mathrm{min}$, or the presence of syncope.

Abbreviations. IQR, interquartile range; BMI, body mass index; PT-INR, international normalized ratio of prothrombin time; CRP, C-reactive protein; LGIB, lower gastrointestinal bleeding; IBD, inflammatory bowel disease; TIA, transient ischemic attack; COPD, chronic obstructive pulmonary disease; AIDS, acquired immune deficiency syndrome; NSAIDs, nonsteroid anti-inflammatory drugs; COX, Celecoxib; DOACs, direct oral anticoagulants. 
Table 2 CT and endoscopic diagnosis

\begin{tabular}{|c|c|c|c|}
\hline Factor & Value & $\begin{array}{l}\text { Data } \\
\text { available } \\
\text { for } \\
\text { analysis } \\
\end{array}$ & $\begin{array}{l}\text { Missing } \\
\text { value }\end{array}$ \\
\hline CT of the abdomen/pelvis & $7,149(69.1)$ & 10,342 & 0 \\
\hline Contrast enhanced CT & $5,240(73.3)$ & 7,149 & 0 \\
\hline Urgent CT & $6,968(97.5)$ & 7,149 & 0 \\
\hline Time to CT scan, hours & $1(1-2)$ & 7,149 & 0 \\
\hline Extravasation on CT & $1,151(22.0)$ & 5,240 & 0 \\
\hline Extravasation at jejunum & $7(0.1)$ & 5,240 & 0 \\
\hline Extravasation at ileum & $57(1.1)$ & 5,240 & 0 \\
\hline Extravasation at cecum & $53(1.0)$ & 5,240 & 0 \\
\hline Extravasation at ascending & $547(10.4)$ & 5,240 & 0 \\
\hline Extravasation at transverse & $83(1.6)$ & 5,240 & 0 \\
\hline Extravasation at descending & $138(2.6)$ & 5,240 & 0 \\
\hline Extravasation at sigmoid & $224(4.3)$ & 5,240 & 0 \\
\hline Extravasation at rectum & $49(0.9)$ & 5,240 & 0 \\
\hline Extravasation at upper GI tract & $1(0.02)$ & 5,240 & 0 \\
\hline Colonic diverticular bleeding on CT & $1,846(25.8)$ & 7,149 & 0 \\
\hline Enterocolitis on CT & $953(13.3)$ & 7,149 & 0 \\
\hline Tumor lesion on CT & $90(1.3)$ & 7,149 & 0 \\
\hline Other diagnosis on CT & $190(2.7)$ & 7,149 & 0 \\
\hline Initial colonoscopic examination & $9,066(87.7)$ & 10,342 & 0 \\
\hline Time to $1^{\text {st }}$ colonoscopy, hours & $16(4-32)$ & 9,066 & 0 \\
\hline SRH on initial endoscopy & $2,801(30.9)$ & 9,066 & 0 \\
\hline SRH, active bleeding & $1,489(16.4)$ & 9,066 & 0 \\
\hline SRH, visible vessel & $535(5.9)$ & 9,066 & 0 \\
\hline SRH, adherent clot & $829(9.1)$ & 9,066 & 0 \\
\hline Location of SRH, cecum & $163(1.8)$ & 9,066 & 0 \\
\hline Location of SRH, ascending & $1,166(12.9)$ & 9,066 & 0 \\
\hline Location of SRH, transverse & $262(2.9)$ & 9,066 & 0 \\
\hline Location of SRH, descending & $182(2.0)$ & 9,066 & 0 \\
\hline Location of SRH, sigmoid & $630(7.0)$ & 9,066 & 0 \\
\hline Location of SRH, rectum & $349(3.9)$ & 9,066 & 0 \\
\hline Location of SRH, jejunum & $5(0.06)$ & 9,066 & 0 \\
\hline Location of SRH, ileum & $94(1.0)$ & 9,066 & 0 \\
\hline Location of SRH, upper GI & $1(0.01)$ & 9,066 & 0 \\
\hline Secondary colonoscopic examination & $1,992(19.2)$ & 10,342 & 0 \\
\hline Time to $2^{\text {nd }}$ colonoscopy, hours & $53(29-96)$ & 1,992 & 0 \\
\hline \multicolumn{4}{|l|}{ Final diagnosis } \\
\hline Colonic diverticular bleeding & $6,575(63.6)$ & 10,342 & 0 \\
\hline Definitive diverticular bleeding & $2,386(23.1)$ & 10,342 & 0 \\
\hline Presumptive diverticular bleeding & $4,189(40.5)$ & 10,342 & 0 \\
\hline Ischemic colitis & $941(9.1)$ & 10,342 & 0 \\
\hline
\end{tabular}




\begin{tabular}{|c|c|c|c|}
\hline Post-procedure bleeding & $463(4.5)$ & 10,342 & 0 \\
\hline Post-ESD bleeding & $140(1.4)$ & 10,342 & 0 \\
\hline Post-polypectomy bleeding & $73(0.7)$ & 10,342 & 0 \\
\hline Post-EMR bleeding, & $223(2.2)$ & 10,342 & 0 \\
\hline Post-biopsy bleeding & $16(0.2)$ & 10,342 & 0 \\
\hline Post-other procedure bleeding & $12(0.1)$ & 10,342 & 0 \\
\hline Rectal ulcer & $257(2.5)$ & 10,342 & 0 \\
\hline IBD & $210(2.0)$ & 10,342 & 0 \\
\hline Hemorrhoid bleeding & $184(1.8)$ & 10,342 & 0 \\
\hline Colorectal angioectasia & $133(1.3)$ & 10,342 & 0 \\
\hline Colorectal malignancy & $193(1.9)$ & 10,342 & 0 \\
\hline Colorectal cancer & $168(1.6)$ & 10,342 & 0 \\
\hline Metastatic tumor & $16(0.2)$ & 10,342 & 0 \\
\hline Other colorectal tumor* & $9(0.1)$ & 10,342 & 0 \\
\hline Colorectal polyp & $37(0.4)$ & 10,342 & 0 \\
\hline Infectious colitis & $134(1.3)$ & 10,342 & 0 \\
\hline Radiation colitis & $66(0.6)$ & 10,342 & 0 \\
\hline Non-specific colitis & $47(0.5)$ & 10,342 & 0 \\
\hline Drug-induced ulcer & $14(0.1)$ & 10,342 & 0 \\
\hline Non-specific ulcer & $56(0.5)$ & 10,342 & 0 \\
\hline Colorectal varix & $25(0.2)$ & 10,342 & 0 \\
\hline Dieulafoy ulcer & $12(0.1)$ & 10,342 & 0 \\
\hline Postoperative anastomotic bleeding & $14(0.1)$ & 10,342 & 0 \\
\hline Anal bleeding other than hemorrhoids** & $12(0.1)$ & 10,342 & 0 \\
\hline Diverticulitis & $7(0.1)$ & 10,342 & 0 \\
\hline Small bowel bleeding & $246(2.4)$ & 10,342 & 0 \\
\hline Small bowel bleeding (definitive) & $114(1.1)$ & 10,342 & 0 \\
\hline Small bowel bleeding (presumptive) & $121(1.2)$ & 10,342 & 0 \\
\hline Meckel's diverticular bleeding & $11(0.1)$ & 10,342 & 0 \\
\hline UGIB & $153(1.5)$ & 10,342 & 0 \\
\hline Other diagnosis*** & $37(0.4)$ & 10,342 & 0 \\
\hline Unknown & $526(5.1)$ & 10,342 & 0 \\
\hline Missing data & 0 & 10,342 & 0 \\
\hline
\end{tabular}

Note. *Other tumor included 4 diseases; malignant lymphoma $(\mathrm{n}=2)$, gastrointestinal stromal tumor $(\mathrm{n}=1)$, pseudomyxoma of the appendix $(\mathrm{n}=1)$, and submucosal tumor unknown origin $(\mathrm{n}=5)$.

**Anal bleeding other than hemorrhoids included 3 diseases; anal laceration or fissure $(\mathrm{n}=10)$, post-anal surgery bleeding $(\mathrm{n}=1)$, and anal condyloma $(\mathrm{n}=1)$.

***Other diagnosis included 15 diseases; mucosal bleeding $(\mathrm{n}=8)$, mucosal prolapse syndrome $(n=6)$, colorectal laceration $(n=4)$, fistula or penetration into colorectum $(n=3)$, colorectal perforation $(n=2)$, mucosal lymphoid hyperplasia $(n=2)$, Kaposi's sarcoma $(n=1)$, stoma-related bleeding $(n=2)$, pseudoaneurysm $(n=2)$, intussusception $(n=1)$, postoperative stenosis $(n=1)$, graft-versus-host disease $(n=1)$, hematoma $(n=2)$, Henoch-Schönlein purpura $(n=1)$, CronkhiteCanada syndrome $(\mathrm{n}=1)$.

Abbreviations. IQR, interquartile range; CT, computer tomography; SRH, stigmata of recent hemorrhage; ESD, endoscopic submucosal dissection; EMR, endoscopic mucosal resection; 
medRxiv preprint doi: https://doi.org/10.1101/2021.01.18.21250035; this version posted January 20, 2021. The copyright holder for this preprint (which was not certified by peer review) is the author/funder, who has granted medRxiv a license to display the preprint in perpetuity.

It is made available under a CC-BY-NC-ND 4.0 International license .

IBD, inflammatory bowel disease; UGIB, upper gastrointestinal bleeding. 
Table 3 Pre-endoscopic procedures, endoscopic procedures, and non-endoscopic procedures

\begin{tabular}{|c|c|c|c|}
\hline Factor & Value & $\begin{array}{l}\text { Data } \\
\text { available } \\
\text { for } \\
\text { analysis }\end{array}$ & $\begin{array}{l}\text { Missing } \\
\text { value }\end{array}$ \\
\hline Bowel prep, PEG or enema & $7,595(83.8)$ & 9,066 & 0 \\
\hline Bowel prep, PEG & $6,022(66.4)$ & 9,066 & 0 \\
\hline Bowel prep, enema & $1,731(19.1)$ & 9,066 & 0 \\
\hline Endoscopic cap use & $6,537(72.1)$ & 9,066 & 0 \\
\hline Endoscopic cap use, long & $1,822(20.1)$ & 9,066 & 0 \\
\hline Endoscopic cap use, short & $4,638(51.2)$ & 9,066 & 0 \\
\hline Endoscopic cap use, ST hood & $69(0.8)$ & 9,066 & 0 \\
\hline Endoscopic cap use, other & $8(0.1)$ & 9,066 & 0 \\
\hline Waterjet scope use & $6,971(77.0)$ & 9,066 & 0 \\
\hline PEG use in water jet scope & $390(4.3)$ & 9,066 & 0 \\
\hline Conservative therapy after endoscopy & $6,092(67.2)$ & 9,066 & 0 \\
\hline Endoscopic therapy & $2,784(30.7)$ & 9,066 & 0 \\
\hline Clipping & $1759(63.8)$ & 2,784 & 0 \\
\hline Indirect clipping & $1,212(43.5)$ & 2,784 & 0 \\
\hline Direct clipping & $547(19.7)$ & 2,784 & 0 \\
\hline Band ligation & $674(24.2)$ & 2,784 & 0 \\
\hline Snare ligation & $109(3.9)$ & 2,784 & 0 \\
\hline HSE & $50(1.8)$ & 2,784 & 0 \\
\hline OTSC & 0 & 2,784 & 0 \\
\hline Coagulation & $228(8.2)$ & 2,784 & 0 \\
\hline Other endoscopic therapy* & $20(0.7)$ & 2,784 & 0 \\
\hline Success of endoscopic therapy & $2,663(95.7)$ & 2,784 & 0 \\
\hline Failure of endoscopic therapy & $121(4.4)$ & 2,784 & 0 \\
\hline Treatment for failure, clipping & $77(63.6)$ & 121 & 0 \\
\hline Treatment for failure, band ligation & $8(6.6)$ & 121 & 0 \\
\hline Treatment for failure, HSE & $14(11.6)$ & 121 & 0 \\
\hline Treatment for failure, OTSC & $1(0.8)$ & 121 & 0 \\
\hline Treatment for failure, coagulation & $8(6.6)$ & 121 & 0 \\
\hline Treatment for failure, other therapy & $11(9.1)$ & 121 & 0 \\
\hline Post-endoscopy perforation & $13(0.1)$ & 9,066 & 0 \\
\hline Post-endoscopy diverticulitis & $3(0.03)$ & 9,066 & 0 \\
\hline IVR & $143(1.4)$ & 10,342 & 0 \\
\hline Surgery & $101(1.0)$ & 10,342 & 0 \\
\hline Barium impaction therapy & $66(0.6)$ & 10,342 & 0 \\
\hline Endoscopic therapy during hospitalization & $3,379(32.7)$ & 10,342 & 0 \\
\hline IVR need during hospitalization & $217(2.1)$ & 10,342 & 0 \\
\hline Surgery need during hospitalization & $142(1.4)$ & 10,342 & 0 \\
\hline
\end{tabular}

Note. Pre-endoscopic and endoscopic procedures were evaluated among patients who underwent endoscopy $(\mathrm{n}=9,066)$. *Other endoscopic therapy included hot biopsy, polypectomy, 
medRxiv preprint doi: https://doi.org/10.1101/2021.01.18.21250035; this version posted January 20, 2021. The copyright holder for this preprint (which was not certified by peer review) is the author/funder, who has granted medRxiv a license to display the preprint in perpetuity.

It is made available under a CC-BY-NC-ND 4.0 International license.

endoscopic mucosal resection.

Abbreviations. IQR, interquartile range; PEG, polyethylene glycol; HSE, hypertonic saline epinephrine; OTSC, over the scope clip; IVR, interventional radiology 
Tables 4 Clinical outcomes

\begin{tabular}{|c|c|c|c|}
\hline Factor & Value & $\begin{array}{l}\text { Data } \\
\text { available } \\
\text { for } \\
\text { analysis }\end{array}$ & $\begin{array}{l}\text { Missing } \\
\text { value }\end{array}$ \\
\hline In-hospital rebleeding & $1,573(15.2)$ & 10,342 & 0 \\
\hline 2nd rebleeding during hospitalization & $458(4.4)$ & 10,342 & 0 \\
\hline Out-of-hospital rebleeding & $2,650(25.6)$ & 10,342 & 0 \\
\hline $\begin{array}{l}\text { Num of out-of-hospital rebleeding episodes, } \\
1-4\end{array}$ & $2,372(22.9)$ & 10,342 & 0 \\
\hline $\begin{array}{l}\text { Num of out-of-hospital rebleeding episodes, } \\
5-9\end{array}$ & $178(1.7)$ & 10,342 & 0 \\
\hline $\begin{array}{l}\text { Num of out-of-hospital rebleeding episodes, } \\
\geq 10\end{array}$ & $100(1.0)$ & 10,342 & 0 \\
\hline Occurrence of thromboembolism & $65(0.6)$ & 10,342 & 0 \\
\hline Occurrence of acute coronary syndrome & $19(0.2)$ & 10,342 & 0 \\
\hline Occurrence of cerebrovascular disease & $28(0.3)$ & 10,342 & 0 \\
\hline Occurrence of PE/ DVT & $18(0.2)$ & 10,342 & 0 \\
\hline In-hospital death & $97(0.9)$ & 10,342 & 0 \\
\hline GI bleeding related death & $13(13.4)$ & 97 & 0 \\
\hline Out-of-hospital death & $694(6.8)$ & 10,245 & 0 \\
\hline $\begin{array}{l}\text { Follow-up days after discharge, median } \\
\text { (IQR) }\end{array}$ & $239(21-809)$ & 10,245 & 0 \\
\hline Blood transfusion & $3,080(29.8)$ & 10,342 & 0 \\
\hline Number of blood transfusions, median (IQR) & $4(2-8)$ & 3,080 & 0 \\
\hline Blood transfusion received $\geq 4$ units & $2,291(22.2)$ & 10,342 & 0 \\
\hline Length of stay, median (IQR, range) & $7(5-11)$ & 10,342 & 0 \\
\hline Prolonged length of stay $\geq 8$ days & $4,744(45.9)$ & 10,342 & 0 \\
\hline
\end{tabular}

Abbreviations. IQR, interquartile range; PE, pulmonary embolism; DVT, deep vein thrombosis 
Table 5 Association between clinical outcomes and final diagnosis

\begin{tabular}{|c|c|c|c|c|c|c|c|c|c|c|c|c|}
\hline & \multicolumn{3}{|c|}{ Hemodynamic instability* } & \multicolumn{3}{|c|}{30 day-rebleeding } & \multicolumn{3}{|c|}{ Thromboembolism } & \multicolumn{3}{|c|}{ In-hospital mortality } \\
\hline & Absent & Present & $\mathrm{P}$ & Absent & Present & $\mathrm{P}$ & Absent & Present & $\mathrm{P}$ & Absent & Present & $\mathrm{P}$ \\
\hline $\begin{array}{l}\text { Colonic diverticular } \\
\text { bleeding }\end{array}$ & $\begin{array}{l}1,032 \\
(27.4)\end{array}$ & $\begin{array}{l}2,014 \\
(30.6)\end{array}$ & 0.001 & $325(8.6)$ & $\begin{array}{l}1,501 \\
(22.8)\end{array}$ & $<0.001$ & $27(0.7)$ & $38(0.6)$ & 039 & $81(2.2)$ & $16(0.2)$ & $<0.001$ \\
\hline Ischemic colitis & $\begin{array}{l}2,860 \\
(30.4) \\
\end{array}$ & $186(19.8)$ & $<0.001$ & $\begin{array}{l}1,796 \\
(19.1) \\
\end{array}$ & $30(3.2)$ & $<0.001$ & $61(0.7)$ & $4(0.4)$ & 0.52 & $94(0.3)$ & $3(0.9)$ & 0.033 \\
\hline Malignancy & $2993(29.5)$ & $53(27.5)$ & 0.54 & $\begin{array}{l}1,812 \\
(17.9)\end{array}$ & $14(7.2)$ & $<0.001$ & $61(0.6)$ & $4(2.1)$ & 0.033 & $82(7.8)$ & $15(0.9)$ & $<0.001$ \\
\hline Infectious colitis & $\begin{array}{l}3,002 \\
(29.4)\end{array}$ & $44(32.80)$ & 0.387 & $\begin{array}{l}1,823 \\
(17.9)\end{array}$ & $3(2.2)$ & $<0.001$ & $64(0.6)$ & $1(0.8)$ & 0.573 & $94(2.2)$ & $3(0.9)$ & 0.131 \\
\hline IBD & $\begin{array}{l}2,977 \\
(29.4) \\
\end{array}$ & $69(32.9)$ & 0.274 & $\begin{array}{l}1,809 \\
(17.9)\end{array}$ & $17(8.1)$ & $<0.001$ & $64(0.6)$ & $1(0.5)$ & 1 & $97(1.0)$ & 0 & 0.27 \\
\hline Radiation colitis & $\begin{array}{l}3,035 \\
(29.5)\end{array}$ & $11(16.7)$ & 0.022 & $\begin{array}{l}1,814 \\
(17.7)\end{array}$ & $12(18.2)$ & 0.911 & $65(0.6)$ & 0 & 1 & $97(0.9)$ & 0 & 1 \\
\hline Other colitis & $\begin{array}{l}3,010 \\
(29.4)\end{array}$ & $36(30.8)$ & 0.753 & $\begin{array}{l}1,816 \\
(17.8)\end{array}$ & 10 (98.6) & 0.009 & $65(0.6)$ & 0 & 1 & $95(0.9)$ & $2(1.7)$ & 0.3 \\
\hline $\begin{array}{l}\text { Colorectal } \\
\text { angioectasia }\end{array}$ & $\begin{array}{l}3,010 \\
(29.5)\end{array}$ & $36(27.1)$ & 0.544 & $\begin{array}{l}1,803 \\
(17.7)\end{array}$ & $23(17.3)$ & 0.912 & $64(0.6)$ & $1(0.8)$ & 0.57 & $95(0.9)$ & $2(1.5)$ & 0.355 \\
\hline Rectal ulcer & $\begin{array}{l}2,966 \\
(29.4)\end{array}$ & $80(31.1)$ & 0.551 & $\begin{array}{l}1,773 \\
(17.6)\end{array}$ & $48(18.7)$ & 0.664 & $63(0.6)$ & $2(0.8)$ & 0.677 & $84(0.8)$ & $13(5.1)$ & $<0.001$ \\
\hline Hemorrhoids & $\begin{array}{l}2,991 \\
(29.4)\end{array}$ & $55(29.9)$ & 0.895 & $\begin{array}{l}1,813 \\
(17.9)\end{array}$ & $13(7.1)$ & $<0.001$ & $63(0.6)$ & $2(1.1)$ & 0.322 & $97(1.0)$ & 0 & 0.422 \\
\hline $\begin{array}{l}\text { Post-endoscopy } \\
\text { bleeding }\end{array}$ & $\begin{array}{l}2,934 \\
(29.7)\end{array}$ & $112(24.2)$ & 0.011 & $\begin{array}{l}1,802 \\
(18.2)\end{array}$ & $24(5.2)$ & $<0.001$ & $65(0.7)$ & 0 & 0.12 & $97(1.0)$ & 0 & 0.023 \\
\hline $\begin{array}{l}\text { Small bowel } \\
\text { bleeding }\end{array}$ & $\begin{array}{l}2,962 \\
(29.3)\end{array}$ & $84(34.2)$ & 0.102 & $\begin{array}{l}1,771 \\
(17.5)\end{array}$ & $55(22.4)$ & 0.05 & $62(0.6)$ & $3(1.2)$ & 0.201 & $93(0.9)$ & $4(1.6)$ & 0.295 \\
\hline UGIB & $\begin{array}{l}2,959 \\
(29.0) \\
\end{array}$ & 87 (56.9) & $<0.001$ & $\begin{array}{l}1,821 \\
(17.9) \\
\end{array}$ & $5(3.3)$ & $<0.001$ & $61(0.6)$ & $4(2.6)$ & 0.016 & $89(0.9)$ & $8(5.2)$ & $<0.001$ \\
\hline Others & $\begin{array}{l}2,867 \\
(29.6)\end{array}$ & $179(26.7)$ & 0.108 & $\begin{array}{l}1,755 \\
(18.2)\end{array}$ & $71(10.6)$ & $<0.001$ & $60(0.6)$ & $5(0.8)$ & 0.612 & $66(0.7)$ & $31(4.6)$ & $<0.001$ \\
\hline
\end{tabular}




\begin{tabular}{|c|c|c|c|c|c|c|c|c|c|c|c|c|}
\hline & \multicolumn{3}{|c|}{ Endoscopic therapy need } & \multicolumn{3}{|c|}{ Surgery need } & \multicolumn{3}{|l|}{ IVR need } & \multicolumn{3}{|c|}{ Transfusion need } \\
\hline & Absent & Present & $\mathrm{P}$ & Absent & Present & $\mathrm{P}$ & Absent & Present & $\mathrm{P}$ & Absent & Present & $\mathrm{P}$ \\
\hline $\begin{array}{l}\text { Colonic diverticular } \\
\text { bleeding }\end{array}$ & $935(24.8)$ & $\begin{array}{l}2,444 \\
(37.2)\end{array}$ & $<0.001$ & $97(2.6)$ & $45(0.7)$ & $<0.001$ & $41(1.1)$ & $176(2.7)$ & $<0.001$ & $974(25.9)$ & $\begin{array}{l}2,106 \\
(32.0)\end{array}$ & $<0.001$ \\
\hline Ischemic colitis & $\begin{array}{l}3,374 \\
(35.9)\end{array}$ & $5(0.5)$ & $<0.001$ & $135(1.4)$ & $7(0.7)$ & 0.082 & $216(2.3)$ & $1(0.1)$ & $<0.001$ & $\begin{array}{l}3,042 \\
(32.4)\end{array}$ & $38(4.0)$ & $<0.001$ \\
\hline Malignancy & $\begin{array}{l}3,358 \\
(33.1)\end{array}$ & $21(10.9)$ & $<0.001$ & $110(1.1)$ & $32(16.6)$ & $<0.001$ & $215(2.1)$ & $2(1.0)$ & 0.445 & $\begin{array}{l}3,005 \\
(29.6)\end{array}$ & $75(38.9)$ & 0.005 \\
\hline Infectious colitis & $\begin{array}{l}3,378 \\
(33.1)\end{array}$ & $1(0.8)$ & $<0.001$ & $140(1.4)$ & $2(1.5)$ & 0.707 & $217(2.1)$ & 0 & 0.12 & $\begin{array}{l}3,067 \\
(30.1)\end{array}$ & $13(9.7)$ & $<0.001$ \\
\hline IBD & $\begin{array}{l}3,371 \\
(33.3)\end{array}$ & $8(3.8)$ & $<0.001$ & $136(1.3)$ & $6(2.9)$ & 0.062 & $215(2.1)$ & $2(1.0)$ & 0.331 & $\begin{array}{l}3,048 \\
(30.1)\end{array}$ & $32(15.2)$ & $<0.001$ \\
\hline Radiation colitis & $\begin{array}{l}3,327 \\
(32.4)\end{array}$ & $52(78.8)$ & $<0.001$ & $142(1.4)$ & 0 & 1.000 & $217(2.1)$ & 0 & 0.65 & $3,61(29.8)$ & $19(28.8)$ & 0.859 \\
\hline Other colitis & $\begin{array}{l}3,351 \\
(32.8)\end{array}$ & $28(23.9)$ & 0.043 & $141(1.4)$ & $1(0.9)$ & 1 & $217(2.1)$ & 0 & 0.182 & $\begin{array}{l}3,041 \\
(29.7)\end{array}$ & $39(33.3)$ & 0.398 \\
\hline Angioectasia & $\begin{array}{l}3,217 \\
(31.9)\end{array}$ & $162(63.0)$ & $<0.001$ & $144(1.4)$ & 0 & 0.267 & $215(2.1)$ & $2(1.5)$ & 1.000 & $\begin{array}{l}3,001 \\
(29.4)\end{array}$ & $79(59.4)$ & $<0.001$ \\
\hline Rectal ulcer & $\begin{array}{l}3,291 \\
(32.0)\end{array}$ & $163(62.9)$ & $<0.001$ & $137(1.4)$ & $5(2.0)$ & 0.406 & $215(2.1)$ & $2(0.8)$ & 0.182 & $\begin{array}{l}2,952 \\
(29.3)\end{array}$ & $128(49.8)$ & $<0.001$ \\
\hline Hemorrhoids & $\begin{array}{l}3,369 \\
(33.2)\end{array}$ & $10(5.4)$ & $<0.001$ & $134(1.3)$ & $8(4.4)$ & $<0.001$ & $217(2.1)$ & 0 & 0.035 & $\begin{array}{l}3,036 \\
(29.9)\end{array}$ & $44(23.9)$ & 0.079 \\
\hline $\begin{array}{l}\text { Post-endoscopy } \\
\text { bleeding }\end{array}$ & $\begin{array}{l}2,963 \\
(30.0)\end{array}$ & $416(89.9)$ & $<0.001$ & $140(1.4)$ & $2(0.4)$ & 0.097 & $216(2.2)$ & $1(0.2)$ & 0.001 & $\begin{array}{l}3,041 \\
(30.8)\end{array}$ & $39(8.4)$ & $<0.001$ \\
\hline $\begin{array}{l}\text { Small bowel } \\
\text { bleeding }\end{array}$ & $\begin{array}{l}3,322 \\
(33.3) \\
\end{array}$ & $57(23.2)$ & 0.001 & $119(1.2)$ & $23(9.4)$ & $<0.001$ & $198(2.0)$ & $19(7.6)$ & $<0.001$ & $\begin{array}{l}2,943 \\
(29.2) \\
\end{array}$ & $137(55.7)$ & $<0.001$ \\
\hline UGIB & $\begin{array}{l}3,378 \\
(33.2)\end{array}$ & $1(0.7)$ & $<0.001$ & $140(1.4)$ & $2(1.3)$ & 1.000 & $214(2.1)$ & $3(2.0)$ & 1.000 & $\begin{array}{l}2,993 \\
(29.4)\end{array}$ & $87(56.9)$ & $<0.001$ \\
\hline Others & $\begin{array}{l}3,302 \\
(34.1)\end{array}$ & $77(11.5)$ & $<0.001$ & $133(1.4)$ & $9(1.3)$ & 0.945 & $208(2.2)$ & $9(1.3)$ & 0.207 & $\begin{array}{l}2,836 \\
(29.3)\end{array}$ & $244(36.4)$ & $<0.001$ \\
\hline
\end{tabular}

Note. For the analysis of the association between bleeding etiologies and outcomes, etiologies that have > 50 cases were included. 
*Hemodynamic instability was defined as initial systolic blood pressure $<90 \mathrm{~mm} \mathrm{Hg}$, initial heart rate $\geq 100 / \mathrm{min}$, or the presence of syncope.

Abbreviations. IBD, inflammatory bowel disease; UGIB, upper gastrointestinal bleeding. 